\title{
ARQUEOLOGÍA CULTURAL DE LOS VIDEOJUEGOS. Entre discursos nostálgicos, experiencia del gamer e innovación tecnológica
}

\author{
Simone BELLI*; Cristian LÓPEZ RAVENTÓS** \\ "Yachay Tech (Ecuador). "*universidad Autónoma Nacional de México (México) \\ sbelli@yachaytech.edu.ec, clopezr@enesmorelia.unam.mx
}

CULTURAL ARCHAEOLOGY OF VIDEO GAMES: between nostalgic discourse, gamer experience and technological innovation

Resumen: En este trabajo, se presentara una historia de los videojuegos como una innovación más allá de una forma de entretenimiento, ofreciendo razones acerca de por qué es importante conocer e investigar su historia en relación a sus contextos sociales y culturales. Haciendo énfasis en la importancia que los usuarios tienen a la hora de crear videojuegos a través de su experiencia, cuestionando la masculinidad construida en los primeros videojuegos y la ausencia, o menor participación, del género femenino en las primeras décadas. El contexto social y cultural en que nacieron aquellos videojuegos es básico para entender la difusión y la popularidad que obtuvieron en los años ' 80 y sobre todo, en los ' 90 . El objetivo de este trabajo es identificar las estrategias de comunicación y de información respecto a los videojuegos antes de la llegada de Internet, en especial la forma y el cómo se compartía esta información en el contexto español. En la primera parte introducimos el marco teórico y metodológico en que se basa esta investigación a través del concepto de arqueología cultural. En la segunda parte presentamos los relatos construidos por los usuarios para analizar las experiencias del juego y la forma de compartirlo, utilizando los conceptos de playformance y playworld. Para finalizar cuestionando la identidad del gamer como sujeto masculino, blanco y joven de clase media-alta.

Abstract: In this paper, it is presented a videogames history as an innovation beyond a form of entertainment, offering reasons why it is important to know and investigate its history in relation to their social and cultural contexts. Marking the importance that users have when creating video games through their experience, questioning masculinity constructed in the first era of videogames and no or less participation of the female gender in the early decades. The social and cultural context in which those games were born is basic to understanding the spread and gained popularity in the " $80 \mathrm{~s}$ and especially in the '90s. The objective of this study is to identify communication strategies and information about the videogame before the arrival of the Internet and how information was shared in the Spanish context. In the first part we introduce the theoretical and methodological framework in which this research is based through the concept of cultural archeology. In the second part we present stories built by users to analyze the experiences of the game and how to share it, using the concepts of playformance and playworld. To finish questioning the identity of the gamer as a male subject, young white and upper middle class.

Palabras clave: Videojuegos. Arqueología Cultural. Experiencia del Gamer. Retrogaming Videogames. Cultural Archeology. Gamer Experience. Retrogaming 


\section{Introducción}

En el presente artículo, se quiere identificar cómo se jugaba a videojuegos, se hablaba de videojuegos y se compartía información sobre videojuegos en el contexto español antes de la llegada de internet.

Por esta razón, no se trata de trazar una historia "tradicional" de los videojuegos, sino presentar una historia guiada por la experiencia de jugar y compartir el juego con los demás. Presentamos aquí un recorrido narrativo y experiencial de lo que era jugar a videojuegos antes de la llegada de Internet y de la popularización de las consolas en las familias españolas.

En la primera parte introducimos el marco teórico y metodológico en que se basa esta investigación, nos centramos en el concepto de arqueología cultural (Foucault, 1969) para reexaminar los discursos sobre el pasado para reordenar el presente, es decir la historia de los videojuegos desde hoy en día. Por esta razón, utilizamos el concepto de retrogaming (Suominen, 2008, 2012, Juul, 2009), construido a través de discursos nostálgicos y la apropiación de nuevas tecnologías. A través el trabajo etnográfico mediante entrevistas a veinticuatro expertos videojugadores de la década de los '90, trazamos "una" historia de los videojuegos de manera personal e íntima, construida a través emociones y experiencias compartidas por los gamers.

En la segunda parte presentamos una de las tantas historias construidas por los usuarios. Para analizar las experiencias del juego y la forma de compartirlo utilizaremos los conceptos de playformance y playworld (Frasca, 2001a, 2001b).También nos centramos en la denominada "edad de oro del software español" y de la post-edad de oro en el contexto español para ofrecer el panorama donde se sitúa nuestra investigación. También se cuestiona la identidad del gamer como sujeto masculino, blanco y joven de clase media-alta para dejar espacio a nuevas maneras de identificar el gamer de aquella época.

\section{Hacer una arqueología cultural en el ámbito de los videojuegos}

Nuestra tarea aquí es trazar una arqueología cultural (Foucault, 1969, Revel, 2002) a través de discursos nostálgicos y apropiación de nuevas tecnologías. Una arqueología cultural basada en examinar discursos y ordenar el pasado para escribir una historia del presente. Para Bolter y Grusin (2000) las nuevas tecnologías adoptan usos y dinámicas de las viejas tecnologías en el sentido que el desarrollo de las tecnologías puede ser conceptualizado con mayor precisión a través de la corrección.

Esta experiencia la podemos analizar en los discursos generados por los video jugadores de una época muy precisa, la década de los '90. Esta década es la que algunos expertos la llaman retrogaming (Suominen, 2008, 2012; Juul, 2009). Una época que ha generado muchos de los videojuegos que todavía estamos jugando hoy en día. Una época histórica de los videojuegos donde se desarrollan algunas de las sagas más exitosas de toda la historia de los videojuegos. Según las 20 sagas más exitosas elaborada por el periódico The Independent (2014), ocho de las sagas presentadas, encuentran su primera aparición en la década de los '80. Con la saga de Mario en el primer lugar y con fecha 1981.

El retrogaming es un fenómeno capaz de tener impacto en nuestras vidas contemporáneas. Cómo se puede ver en la ilustración 1, el fenómeno del retrogaming tiene impacto en muchos ámbitos de nuestras vidas cotidianas y en los productos culturales que nos rodean (Cinema, música, literatura, ropa, etc.). Hubo

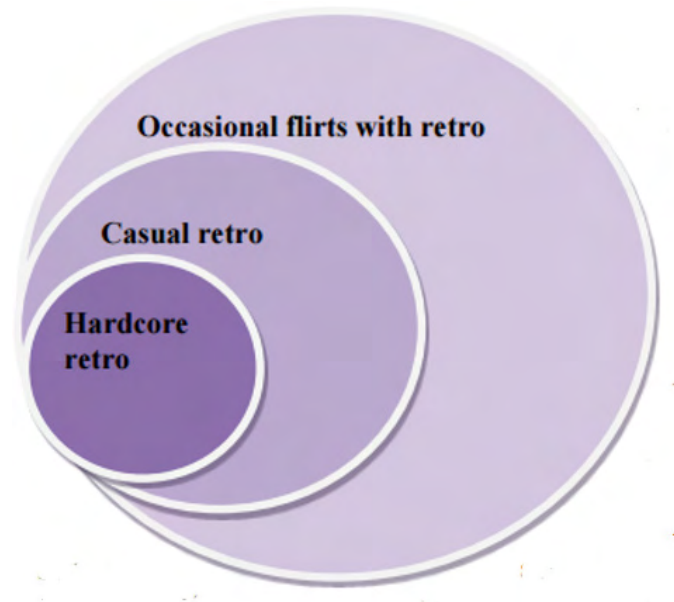

Ilustración 1 Círculos de retrogaming (Suominen, 2012) 
una época, según Suominen (2012), en que los videojuegos generaron un impacto social y cultural en generaciones transnacionales. En su estudio basado en las tres grandes compañías de los años '90, Nintendo, Microsoft y Sony, se pueden observar elementos de los videojuegos de aquella década en muchos ámbitos de nuestras vidas. Suominen categoriza esta presencia utilizando estos tres círculos. Hay productos que ocasionalmente flirtean con los videojuegos retro, hay productos que tienen algunos aspectos similares a los videojuegos de aquella época, y en fin, hay videojuegos que están de manera muy directa influenciada por lo retro. Estos tres círculos tocan diferentes ámbitos relacionados con los videojuegos, desde la jugabilidad a elementos gráficos.

Estos discursos nostálgicos están a la base para identificar esta experiencia del gamer. La nostalgia en los jugadores de la mediana edad por lo que eran los juegos de los años 80 y 90, es la misma que pasan a los que escuchan rock de los años ' 70 . No es que cualquier tiempo pasado fue mejor, sino que la época en que empezaron era el nacimiento de aquel producto, antes de que se volviera popular, y todavía cubría un espacio alternativo, no mainstream, que también se transforma en nostalgia (Suominen, 2012).

Por estas razones, Michel Foucault es la clave para entender estos discursos nostálgicos. La arqueología cultural puede ser definida como el nivel inconsciente de una cultura que permite las formas percibidas reales de la vida cotidiana. El estudio arqueológico permite que objetos, ideas, pensamientos, experiencias, etc. ofrezcan una situación histórica determinada (Foucault, 1969). Hacer una arqueología cultural no solo se refiere a la totalidad de los discursos culturales de una época, sino a las reglas, prácticas, condiciones y funcionamientos que regulan la construcción de eventos culturales determinados (Revel, 2002).

En los Game Studies, Huhtamo (2005a) ha aplicado el método arqueológico para mapear la prehistoria de los videojuegos que empieza con la cultura del siglo diecinueve basada en las máquinas y dispositivos protointeractivos. Aki Järvinen (2001) también presenta su propia arqueología de los juegos, y que nos interesa especialmente aquí porque es una arqueología de los usuarios, los jugadores. Järvinen reconoce que las prácticas de los video jugadores hay que buscarlas en la historia de los primeros videojuegos para ordenador y en las primeras consolas. Para él, la situación del juego es sobre todo una situación estética de ciertas percepciones, afectos y emociones que el juego produce para el jugador. En consecuencia, esto coloca al jugador en una cierta posición de uso que siempre está determinada en parte por las características históricas de mayor duración del juego. En lengua castellana hay una extensa bibliografía relacionada con la experiencia del video jugador pero desde un aspecto educativo y pedagógico, enfocada en justificar la existencia del videojuego como elemento básico en el aprendizaje y no de ocio.

También hay que mencionar que en el contexto del retrogaming se ha realizado también arqueología no solamente cultural, es decir, con excavaciones y expertos arqueólogos, es el caso de Atari y de los cartuchos no comercializados a principio de los años ' 80 y enterrados en Alamogordo, Nuevo México. Resulta que para la Navidad de 1983 se fabricaron 5 millones de cartuchos del videojuego "E.T. el Extra-Terrestre", transposición lúdica de la película de Steven Spielberg. El videojuego fue un auténtico fracaso comercial debido a la falta de tiempo para su desarrollo, cinco semanas, y por esta razón Atari cerró la actividad y enterró miles de cartuchos. En el 2014 se organizó una expedición arqueológica para recuperar estos tesoros pertenecientes al mundo del retrogaming.

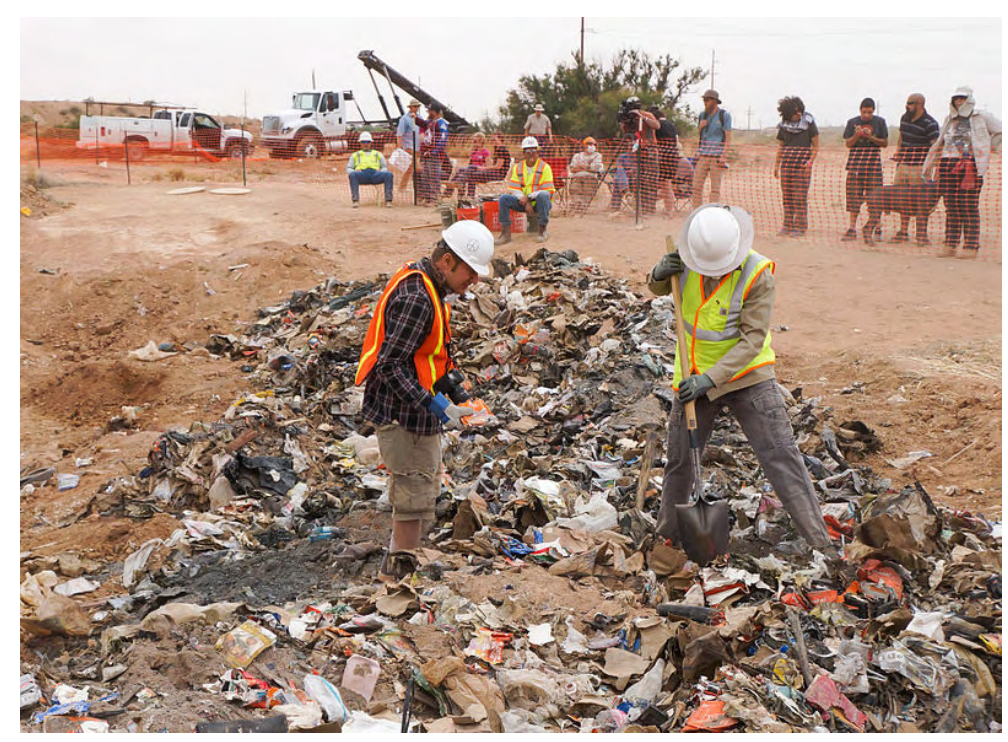

Ilustración 2 Taylorhatmaker - http://www.flickr.com/photos/henofthewoods/14039327125/ 


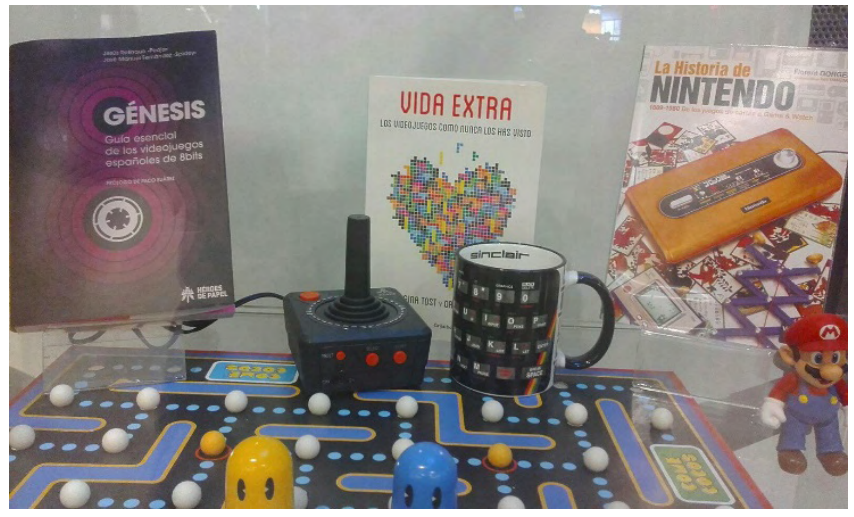

Ilustración 3 Foto: Javier Romano

\section{Metodología}

Hemos realizado un trabajo etnográfico mediante entrevistas a veinticuatro expertos videojugadores de la década de los ' 90 con el objetivo de trazar "una" historia de los videojuegos de manera personal e íntima, construida a través emociones y experiencias compartidas por los gamers. Se trata de trazar una lectura biográfica en relación a los videojuegos. También nos hemos centrado en la construcción del género en los videojuegos, y en qué manera estos videojuegos impactaban la sociedad ${ }^{1}$.

Para realizar estas historias hemos utilizado dos tipos de textos. En primer lugar los producidos en las entrevistas en profundidad a través de las transcripciones de las grabaciones de audio. En segundo lugar las producciones textuales relacionadas con el mundo de los videojuegos de esa época en particular en España. Las dos formas de textos son entendidos como prácticas discursivas (Foucault, 2001). El discurso para Foucault es más una práctica social que un sistema de signos que representan con mayor o menos grado de fidelidad la realidad. Por este motivo se habla de prácticas discursivas, para poner el acento en el habla como constructor de objetos, no sólo como forma de nombrarlas en un acto representacional. Esas prácticas discursivas generan un entramado regulativo que configura en cada momento histórico objetos, reglas y comunidades. Esas prácticas son las que hacen posible que se hable de esos elementos de forma concreta en cada momento histórico. Esa práctica social que es el discurso configura aquello que es posible nombrar y lo que no. Los discurso se convierten en prácticas sociales que crean los objetos de los cuales hablan y nombran (Foucault, 2001).

El análisis del discurso que Foucault presenta funciona en cuatro pasos diferentes: el primero cuestiona el objeto discursivamente producido; el segundo analiza la lógica interna que permite la construcción de estos objetos; el tercero busca a los sujetos que generan y se benefician de esta construcción discursiva; y por último, busca cuáles son los objetivos que llevan implícitos estas prácticas discursivas. Todo este entramado discursivo debe ser entendido dentro de un proceso socio-histórico donde aparecen esas prácticas organizando sistemas normativos o campos de saber determinados, entrelazándose a partir de ese discurso constitutivo y generador de objetos.

Las entrevistas en profundidad fueron elegidas utilizando la técnica de la "bola de nieve" debido a la dificultad para encontrar sujetos con los perfiles específicos. La entrevista en profundidad tenía un guión que quería hacer énfasis en algunas cuestiones centrales en la construcción de las narrativas sobre la experiencia del juego. Los temas principales del guión fueron los lugares dónde, cómo y con qué se empezó a jugar a videojuegos, los medios con los cuáles se informaban sobre el mundo, los géneros preferidos y el motivo de la elección, los vínculos de éstos con la realidad y la percepción que tenían de su actividad en el resto de la sociedad.

Los materiales textuales de la época fueron elegidos por su relevancia a partir de las entrevistas realizadas. Estos materiales se componen de medios de comunicación especializados en videojuegos hasta los manuales de los juegos más relevantes para los videojugadores de la época. Así, la elección de esos materiales no se convierte en un análisis en profundidad de los mismos sino en textos que se conectan entre sí, generando y dando coherencia a las narraciones de la experiencia de los gamers.

\footnotetext{
1 Se agradece al Institut d'Estudis Catalan, a la Societat Catalana d'Historia de la Ciencia i de la Tecnica, a Ignasi Medà Calvet y a todos los expertos de retrogaming que han ofrecido los datos para esta investigación. Para una breve historia de los videojuegos consultar Belli, López (2008). Para mayor detalle de cómo se realizó la excavación se aconseja la visión del documental "Atari Game Over" de Zak Penn (2014).
} 


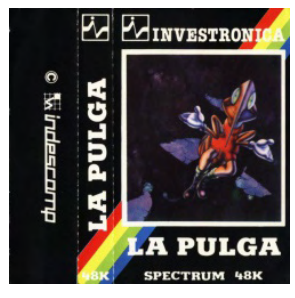

Ilustración 4 portada: Bugaboo- La pulga de 1983

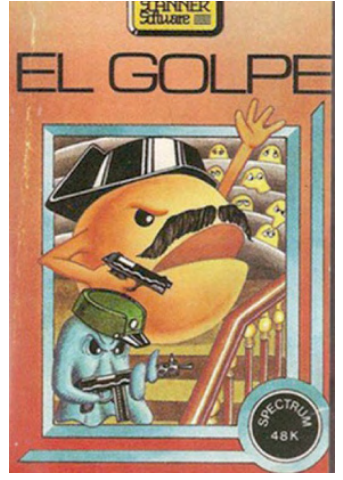

Ilustración 5 portada: El Golpe 1984

\section{La edad y post-edad de oro del software español}

Para esta investigación, tomamos en cuenta las narrativas de algunos de los videojugadores de la época post-edad de oro, es decir, la que aparece justo después de la llamada Edad de oro del software español. Hay que mencionar que esta época se sitúa aproximadamente entre 1983 y 1992, momento durante la cual en España se encontraban la mayoría de los productores europeos de videojuegos, sólo detrás a Reino Unido. Invitamos a los lectores a consultar los textos de Portalo (2009), Gutiérrez (2012), Pedja y Spidey (2015) para profundizar más sobre esta época. Loguidice y Barton (2009) nos ofrecen un profundo y detallado análisis de los juegos de las décadas ' 80 y '90 que seguro interesan a la hora de hacer una arqueología de muchos videojuegos que se comentan aquí. Nosotros nos limitamos a mencionar solamente algunos videojuegos que representan la conexión entre los videojuegos y la sociedad española. Hay que señalar también que el término "edad de oro del software español" fue acuñado por las revistas especializadas de la época que vamos a analizar en los apartados posteriores y que nos resulta interesante para entender cómo se distribuía y se compartía información en aquella época. Uno de los juegos más representativos de esta época, fue Bugaboo- La pulga de 1983, y El Escalador Loco del 1984.

Hay juegos de aquella época que nos demuestran como los videojuegos no solo tienen un impacto en la sociedad, sino que la misma sociedad tiene un impacto en los videojuegos. Por esta razón, la edad de oro no se limita solamente a producir videojuegos descontextualizados, sino todo lo contrario, produce videojuegos que tratan temáticas de aquella época de la sociedad española. El caso de El Golpe es muy representativo y refleja esta bidireccionalidad que acabamos de mencionar y que permite considerar al videojuego como un producto cultural en el sentido antropológico de la palabra.

Se trata de un videojuego que aparece en el 1984 y reproduce a través una parodia el fallido golpe de Estado del 23 de Febrero del 1981 en España. Cómo podemos ver en la misma caratula del videojuego, era muy llamativo y presentaba caricaturas de los mismos protagonistas principales de aquel evento histórico de la sociedad española. Más ejemplos de este impacto bidireccional nos lo ofrecen los juegos como Bull Fight (1984), Olé, Toro (1984) y, aunque fuera de la edad de oro, Chorizos de España (2013) (Navarrete, 2014). La españolidad en los videojuegos nos enseña como muchas veces se exportan modelos culturales a partir de productos de masa.

Hay que decir que la edad de oro coincide con la década de las consolas de 8-bits, y la post-edad de oro se refiere al salto a las consolas de 16-bits, que desencadenó la disolución de muchas compañías españolas a principio de los años '90. Estas videoconsolas de 16 bits dieron un importante salte técnico que muchas

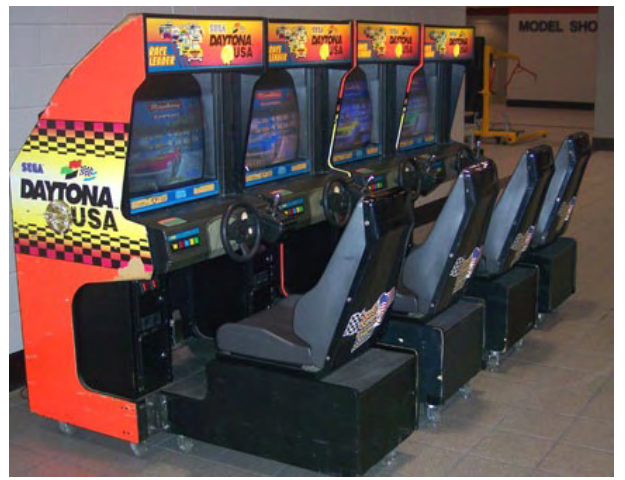

Ilustración 6 Una sala de juego 


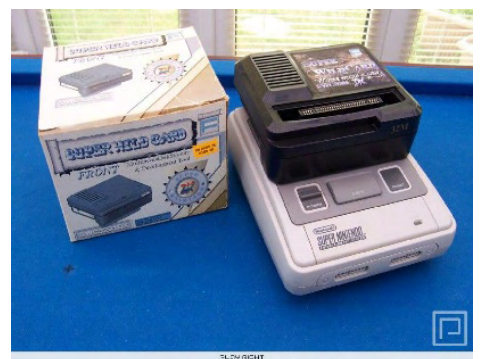

Ilustración 7 la Wildcard para Snes.

empresas españolas no supieron hacer frente.

\section{¿En casa, en el bar o en las salas recreativas?}

El lugar dónde se jugaba representa la primera categoría que podemos observar en las narraciones. Hay un aspecto del juego, basado en la experiencia de jugar en sitios públicos, que ahora ya no tiene el mismo impacto que tenía en las década de los ' 80 y ' 90 . Jugar en los bares o en las salas recreativas servía para la socialización entre los gamers y de los videojuegos:

Oriol: la gente jugaba mucho a máquinas recreativas en bares y en salas recreativas, y de ahí nacía la afición.

Compartían estos espacios físicos de carácter offline, de la misma manera en que ahora compartimos espacios digitales y online gracias a Internet. También el hecho de compartir estos espacios, significaba entrar a contacto con la máquina física que representaba el videojuego. Muchas veces un aparato, o varios aparatos como los que aparecen en las imágenes siguiente.

Las emociones y la interacción experimentadas en la sala de juego era diferente con la versión domestica del juego. La versión doméstica y "coin-op" es abismal (Livingstone, 2002; Newman, 2004). Hacer, tocar y moverse no son simplemente acciones, son maneras de entender el mundo, formas que tiene nuestro organismo de adquirir información y compartir las experiencias vividas.

Es así como toma cuerpo el concepto de playformance, para jugar a videojuegos hay realizar una serie de acciones con todos esos elementos nombrados en el playworld que generan una experiencia concreta de juego. "Hacer, tocar y moverse no son simplemente acciones pero también son maneras de entender el mundo, formas que tiene nuestro organismo de adquirir información y entender el mundo" (Frasca, 2009: 43).

Otro factor era la diferencia abismal entre una consola de 8 bits domésticas y las máquinas que uno encontraba en las salas recreativas:

Jorge: El videojuego del bar era muy diferente que el videojuego doméstico. Las consolas domesticas eran menos potentes.

La prestación y los costes era la principal motivación para que el gamer fuera a estos lugares en vez de quedarse en casa con su consola 8 bits.

También hay que mencionar que no solamente existían estos tres lugares (casa, bar, sala recreativa) sino que aparece en los discursos nostálgicos un cuarto lugar, la casa de los amigos:

Ferran: També pot parlar amb el meu amic Albert o Santi que ells eren els més viciats del poble i tenien lo millor que va passar als anys 90 en videojocs la Wildcard de Snes.

Se trata de unos nodos principales en estas redes que los gamers están construyendo. En sus relatos, aparecen figuras claves, como Albert y Santi, los más populares por tener un emulador de todos los juegos para Snes, una Wildcard. Se trata de un recorrido emocional, de la infancia, de las redes de nuestra niñez, a partir de un relato tecnológico. Hacer arqueología cultural remite a la Wildcard de Snes para construir la red de nuestras primeras décadas de socialización. También podemos averiguar cómo los seres humanos prefieren jugar juntos y compartir el divertimiento en grupo (Pujol, 2010). Y una vez más el videojuego se vuelve social y no de aislamiento.

La ludología no deja de alertar acerca de que la narración no es la única forma de contar cosas, los discursos se transmiten de diversas maneras a partir de las reglas, las estructuras y las experiencias del juego. A esto hay que añadirle dos advertencias que todos los investigadores en videojuegos deberían tener en 
cuenta, "el juego es social y físico" (Frasca, 2009: 42). El juego siempre es con otros, en su presencia física o no, y el juego implica algún tipo de acción performativa.

A través de estos nodos se distribuía información sobre videojuegos. A final de los ' 90 los nodos han cambiado, ya para estar actualizados no se recurre a los chicos más viciados del pueblo, sino la llegada de Internet se transforma en el nodo principal para compartir esta información:

Valeria: Para informarse de videojuegos solía utilizarse el portal EresMas, de Telnet España. Yo solía usar el IRC, MSNGroups y alguno de los primeros foros rudimentarios y chats de Terra.

Viviana: En el foro de Meristation, o en el 96 había una web llamada TrucoTeca.

El contexto en que se comparte la experiencia del video jugador pasa de ser físico a digital, de la casa de los amigos al foro. El gamer experto se digitaliza y comparte su conocimiento en una red mucho más distribuida y abierta. Aparece gracias al juego social, la cooperación entre gamers. La experiencia social de jugar a videojuegos ya no es sólo la actividad de jugar juntos en la misma pantalla, sino también intentar avanzar de nivel compartiendo conocimiento adquirido. Por esta razón se comparten los trucos entre gamers y se hace circular la información en las redes. Los trucos son parte esencial de los mismos juegos, son parte de las reglas no escritas por las que se juega a un juego.

Nuestro acercamiento al estudio de los videojuegos pone en duda la visión pasiva del gamer "impactado" por su práctica del videojuego, por otra activa donde "leemos" nuestro entorno. Nos convertimos en buscadores y creadores de significados que interpretamos en nuestro entorno y que somos capaces de "reescribirlo" al trasladar el resultado de esta lectura a nuestra vida cotidiana. Hay que acercarse al estudio de los videojuegos como herramientas de relación y no de aislamiento. Es decir, al entramado de relaciones de diálogos y emociones que se pueden fomentar a través de estas prácticas de juego, tanto en el ámbito familiar como en otros. Nuestras emociones nos conectan al mundo de la ficción presente en los videojuegos (Tavinor, 2009). De esta manera, los videojuegos son unos objetos en los que se basa la experiencia del video jugador. No tratamos de videojuegos, sino que gracias a ellos podemos explicar la sociedad, las dinámicas sociales y culturales de una época. A partir del objeto y de su uso, hablamos del sujeto. La experiencia del gamer-sujeto es la que permite compartir información entre la comunidad más allá del mero videojuego-objeto.

\section{Distribución de información: las revistas especializadas}

Hablar de videojuegos es realizar un recorrido a veces nostálgico, es hablar de nuestros juguetes pero de una manera más social: a través de los amigos, de las salas de juego, del compartir casetes y trucos. Es algo que viene de nuestra experiencia y de cómo aprendimos a utilizar estas máquinas, estas nuevas tecnologías que nuestros padres no sabían usar, y no nos podían ayudar como cuando aprendimos a ir en bicicleta o a jugar con una pelota. Eran unas competencias que ellos no podían ofrecernos, y teníamos que aprender nosotros mismos con nuestros coetáneos, o algún hermano o primo mayor que nosotros. Por esta razón, las revistas eran fundamentales, nos ayudaban a avanzar en los juegos, a no morir siempre en el mismo salto. A no volver a cometer el mismo error una y otra vez:

Las minas de la primera fase eran infernales. He jugado últimamente y me ha costado mucho pasarlas. Eran otros tiempos. Poner algo así en un juego de ahora haría que el 99\% abandonara a las primeras de cambio. Ignacio Abril, programador de Navy Moves (Pedja y Spidey, 2015).

Muchos de los videojuegos de aquel entonces eran como los describe Ignacio, infernales. Debido a la inexperiencia o también por el hecho de que los videojuegos en un primer momento estaban pensados como máquinas recreacionales para su utilización en los espacios públicos, y por tanto estaban basados en la lógica "Insert Coin", es decir, utilizar el mayor número de monedas en el menor tiempo posible, ahora sería muy difícil encontrar esta tipología en los juegos actuales. Los videojuegos de antaño no permitían salvar los progresos del juego, se limitaban a "tres vidas" por partida, y no tenían la posibilidad de continuar. La consola Atari 2600 sintetiza perfectamente este aspecto nada amigable de los videojuegos de aquel entonces.

Por estas razones, en aquella época sin conexiones wifi, los gamers aprendían como avanzar en los videojuegos a través de las revistas. En las revistas se podría aprender cómo superar el nivel, cuáles eran los trucos y muchas más cosas. También existían las guías (no confundir con las instrucciones del juego), una especie de manuales para acompañar paso a paso los gamers (Consalvo, 2007). 


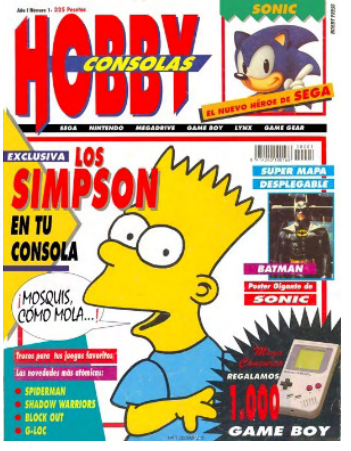

Ilustración 8 Revitas Micro Mania y Hobby Consolas.

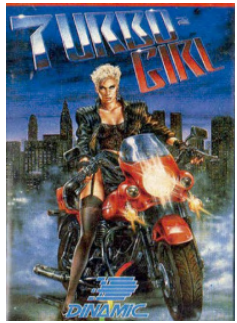

Ilustración 9 Portada Turbo Girl

Las revistas de videojuegos representaban uno de los puentes de conexión entre el videojuego y su público. Lo interesante de aquellas revistas era que trataban los videojuegos de forma mucho más amplia, hablando de la realidad social y otros productos culturales de la sociedad. Uno de los articulistas de aquel entonces nos confirma este aspecto:

El Raffo: Leer una reseña que sólo hable del juego es un coñazo, sobre todo por los juegos de mediana o baja calidad.

Una reseña no trataba sólo el juego sino el público, la sociedad, la experiencia de jugar con más gente que trabajaba en la revista, etc. El mismo comité editorial de las revistas era constituido por jóvenes apasionados de videojuegos, que muchas veces todavía no habían acabado su formación escolar de pregrado. Eran los únicos expertos que se podían encontrar en aquel entonces, adolescentes que jugaban rápido y podían hablar sobre el juego de una manera informal y directa para que los lectores pudieran entender de lo que se estaba hablando. Este aspecto ha cambiado en las revistas actuales, siempre más técnicas y formales:

Victor: Pues sí, recuerdo claramente dos revistas de videojuegos que había en España en esa época: Micromanía y Hobby Consolas. La primera era más de videojuegos de PC y muchas veces incluía un CD con demos de juegos para que la gente los pudiera probar. La segunda era de videoconsolas. Estoy seguro de que en mi casa del pueblo debe haber ejemplares antiguos de las dos (quizás más de los 2000 que de los 90).

En España, los informantes están de acuerdo en coincidir que las dos revistas más emblemáticas eran Micro Mania y Hobby Consolas. Las dos revistas tenían objetivos diferentes, mientras la primera era destinada a unos gamers de PC, la otra era para los de consolas. Lo interesante es que estas revistas muchas veces se guardaban, y se compartían. Muchas veces los juegos que se mencionaban, o los trucos, eran para juegos que todavía no se poseía pero muy probable que en un futuro sí que resultaba útil tener esta información. Por esta razón, el informante nos dice que todavía conserva muchas de aquellas revistas en la casa de su infancia:

Miquel: Aquí a on hem veus va ser la meva època forta dels videojocs la revista més mítica era la Hobby Consolas. Aquesta ho va petar moltíssim era compra obligada perquè a més tenia unes pàgines finals amb tots els jocs que sortien dividit per consola $i$ tu t'imaginaves quin t'anaves a comprar. Altres revistes eran la Micromania y la Pc Mania pero aquesta última era més per empollones perquè de repent tenia articles sobre hardware o coses que no interesaven a ningú.

La "Hobby consolas" es justamente la revista por excelencia de aquella época, lo interesante es que la distribución y comunicación de información sobre los videojuegos se basaba en los estrenos. Esto propiciaba que los gamers pensaran e imaginaran como sería la experiencia de poseer aquel videojuego. Era una forma de ir generando un listado de los futuros videojuegos que el gamer deseaba para próximas compras. El formato típico de estas reseñas era representado por capturas de pantalla del videojuego con un texto que las acompañaba. Al final del texto se cuantificaban los resultados en una escala de 0 a 10 , o de 0 a 100 , los diferentes aspectos del juego como jugabilidad, gráficos, longevidad, sonido, y un total final: 


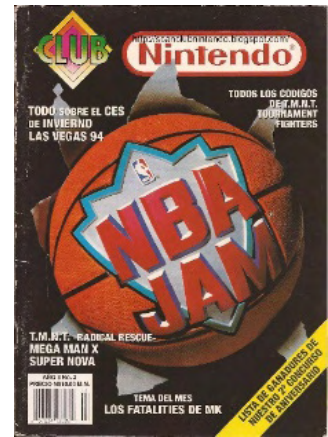

Ilustración 10 Portada NBA JAM

Consolas. Estos eran los tótems; uno era fundamentalmente de ordenadores (cinta primero, luego cartuchos y PC's) La Hobby Consolas, estaba dedicada a las consolas, como podrás haber deducido. La Micromanía creo que se sigue editando, con lo que puede tener como 25 años o más. La Micromania era fundamental: además su formato era como el de un periódico en los noventa, brutal.

A diferencia de la narrativa anterior, donde el gamer expresa su negatividad respecto a las revistas para ordenadores, en este caso tenemos otra experiencia más positiva, indicando que la revista era brutal. De esta manera podemos entender como haciendo arqueología cultural se dibuja una de las tantas historias posibles hablando de productos culturales. Las emociones presentadas en las dos narrativas son totalmente diferentes, pero ambas válidas a la hora de trazar una historia de los videojuegos.

La importancia de las revistas especializadas no era solamente distribuir esta información entre empresas de videojuegos y gamers, sino también para lanzar productos culturales pertenecientes al contexto en que se producen. Un caso emblemático viene representado por las revistas españolas y la edad de oro del software español. A título de ejemplo, el primer número de la revista Micro Mania en 1988 lanzaba uno de los juegos más mediáticos de la Edad de Oro: Turbo Girl.

Se trata en este caso de una sinergia importantísima para competir con otros países, por ejemplo el Reino Unido, Estados Unidos y Japón. Para tener una empresa tecnológica en el sector de los videojuegos es fundamental tener una buena distribución de información en el contexto en que se produce, para dar mayor visibilidad al producto, mayor "salida" comercial. De la misma manera en que otros países empujan sus propios productos al mercado local antes que al internacional. Es fundamental entender la importancia que han tenido las revistas del sector para la Edad de Oro.

A nivel transnacional hay una revista que fue pionera en compartir y distribuir información en diferentes mercados es la revista Nintendo Club. A través de subscripciones anuales, los gamers recibían a su domicilio cada mes un nuevo número de la revista:

Viviana: Recuerdo haber tenido una buena colección de la revista TodoSega y algunos números de la MicroHobby. Muchos de estos me los regalaron porque en ese momento era bastante pequeña (tenía como 6 años en 1994). Más tarde empecé a comprar números de la HobbyConsolas y PlayManía. También estaba la NintendoAcción, aunque no tuve ninguna consola de esa casa hasta el 2000.

Lo interesante de este extracto, es la narración del recorrido que la gamer hace de su experiencia como lectora de revistas especializadas, pero también de video jugadora. Este recorrido pasa por el impacto que tuvieron en su día las revistas multiplataforma, es decir, que informaban sobre los videojuegos por diferentes consolas, a revistas únicamente dedicadas a una sola consola.

Viviana: Load'n'run era otra revista que venía con cassetes de juegos para Spectrum. Stars también era similar a la anterior. Input cubría tres plataformas de videojuegos. La NintendoAcción pasó a llamarse Revista Oficial Nintendo. Y pertenece a la misma editorial que Hobby Consolas, que más tarde empezó a publicar PlayMania, TodoSega y SuperJuegos.

La revista "Nintendo" fue la primera a tener como objetivo de análisis solamente los videojuegos estrenado por las consolas de aquella marca. Desde entonces, aparecieron en el mercado otras revistas destinadas a un público dividido según las consolas. El mercado de los videojuegos empezó a tener diferentes sectores dividido por clientes especializados. Se pasó de un mercado general, donde el lector estaba interesado 
a los videojuegos que se estrenaban independientemente de las consolas en que venían distribuidos, a un mercado en que el gamer quiere saber sobre los videojuegos que se estrenan únicamente para su máquina. También hay que decir que el mercado se amplió notablemente en la década de los '90, más perfiles de gamers aparecieron y la industria de los videojuegos empezó a ser el gran imperio de la industria cultural que conocemos ahora.

Julia: En España Nintendo Acción era una de las revistas más populares y aunque el nombre diga Nintendo había noticias de todas las consolas y próximos videojuegos, también había consejos en las últimas páginas sobre cómo hacer algunas cosas en los videojuegos para desbloquear algún secreto.

Interesante como la revista "Nintendo Acción" pasa de tratar videojuegos multiplataforma en un inicio para después dedicarse solamente a los juegos de sus consolas. Este primer acercamiento es debido a una elección de márquetin para captar audiencia de otras consolas para después direccionarlos en las consolas Nintendo.

Después de esta "edad de oro" de las revistas de videojuegos, a partir del año 2000, los lectores se centran únicamente en revistas ultra especializadas a sólo un tipo de consola. Los gamers no tienen curiosidad por saber lo que se produce en otras plataformas, y de esta manera las revistas se especializan y se vuelven técnicas. Ya no hay artículos más generales sobre los videojuegos y la sociedad, sino que los periodistas que los escriben se convierten en técnicos de videojuegos, utilizando un lenguaje propio y un análisis técnico del juego en cuestión. Se pierde aquella espontaneidad y aquel acercamiento rebelde que tenían los periodistas en un primer momento, y así se pasa a la institucionalización del videojuego como producto de consumo de masa, y por esta razón se vuelve "serio". Ya no hay espacio en una reseña que hable de lo que rodea al videojuego (social, cultural, etc.). De las revistas que se han mencionado a lo largo de las narrativas, algunas ya no existen, otras continúan en formato físico y digital, y otras sólo en formato digital.

\section{Construcción del género: El efecto Birdo y Super Mario Bros 2}

Es importante destacar las aportaciones de la ludología como enfoque dentro de los Games Studies. Gonzalo Frasca (2007) advierte que debemos tener en cuenta dos dimensiones cuando se analizan videojuegos, el playworld y la playformance. El playworld estaría compuesto de todas aquellas partes físicas que componen el juego, imágenes, sonidos, textos, palabras, pero también el cuerpo del jugador y el espacio donde se juega. Según el autor, los estudios sobre juegos en general y videojuegos en particular se han centrado excesivamente en esta dimensión a la hora de estudiarlos. La playformance sería la acción de todos esos elementos durante el juego. Para jugar a videojuegos hay realizar una serie de acciones con todos esos elementos nombrados en el playworld que generan una experiencia concreta de juego.

La identidad del gamer en la década de los noventa era predominada por "lo masculino". Los juegos estaban pensados para un público de hombres jóvenes y blancos de clase media-alta. Por esta razón, nos parece oportuno analizar críticamente la imagen de lo masculino que se construye en estos videojuegos a partir de los ejemplos más emblemáticos que hemos mencionado anteriormente. En este análisis crítico de los videojuegos aparecen casos emblemáticos dignos de ser mencionado en este trabajo para identificar el impacto de la construcción del género en los videojuegos y en la sociedad, una dirección bidireccional que se retroalimenta.

El espacio público para videojugar, salones recreativos en su gran mayoría, son considerados espacios masculinos (Gil \& Feliu, 2006; Gil \& Vida, 2007), lugares diferentes a los espacios de socialización de las chicas. Esta percepción de los espacios donde se encuentran los videojuegos como lugares masculinos genera que las chicas no accedan a ellos, aumentando así la percepción acerca de que los videojuegos son cosa de chicos. Algunos estudios consideran que la formación y consolidación de la identidad "gamer" se produce a gran escala en espacios públicos considerados masculinos como los salones recreativos o las tiendas especializadas (Bryce \& Rutter, 2003). Es importante recordar que estas acusaciones sobre la masculinidad de los espacios recreativos públicos no son nuevas, ya a finales del siglo XIX aparecieron las mismas críticas y prejuicios sobre este tipo de espacios como comenta Huhtamo (2007), incluida la percepción que esos espacios eran exclusivos para hombres.

Si hablamos del espacio privado, en los hogares, podríamos pensar que esas diferencias y prejuicios desaparecen pero no es así. La distribución y uso de los aparatos tecnológicos en las casas suele responder, en parte, al uso de género del que se hablaba anteriormente, donde existían una serie de aparatos relacionados con las mujeres (electrodomésticos, teléfonos) y otros de uso masculino (computadora, videoconsola, televisión) (Gailey, 1993; Na, 2001). Así, con la introducción generalizada de las computadoras personales en las casas se pensó que las chicas tendrían más facilidad para acceder e interesarse por videojuegos (Thomas 

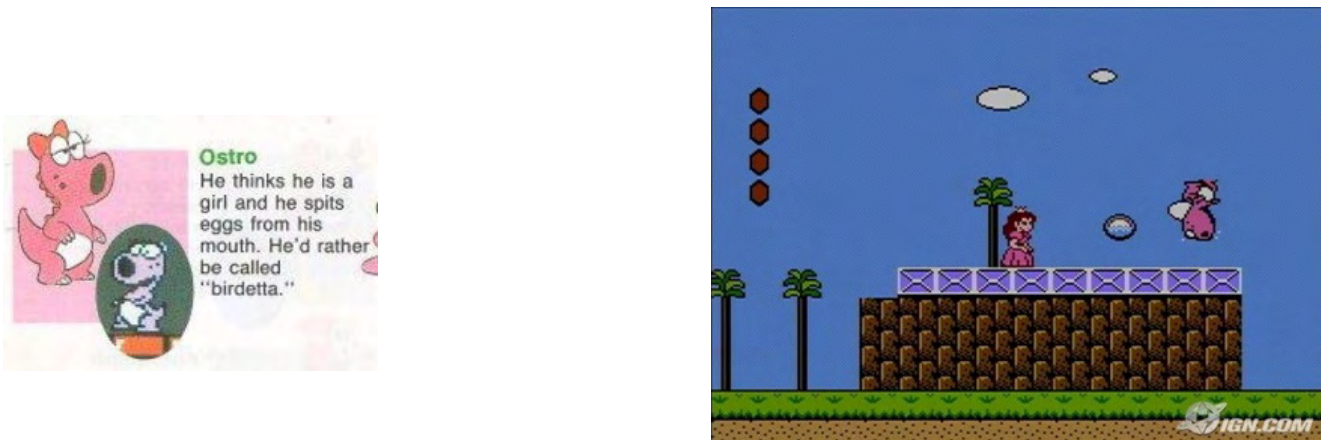

\section{Ilustración 11 La descripción de Birdo en el librito de Ilustración 12 Portada Secuencia Princess Toadstool instrucción de Super Mario Bros 2. \\ Super Mario Bros 2}

\& Walkerdine, 2000). Sin embargo, ese uso de las tecnologías en el hogar vuelve a diferenciarse a partir del género debido a que el uso de la videoconsola se sigue viendo como algo para chicos. El espacio privado se convierte en un espacio no equitativo donde los procesos relacionados con el género se vuelven a reflejar en el acceso y uso de los videojuegos.

Un acercamiento al estudio del género en los videojuegos se ha podido observar sobre el tratamiento de la sexualidad en los videojuegos (Belli, López, Feliu y Gil, 2009), donde se presentan cinco fases de la relación videojuegos y sexualidad en su historia. Desde unos videojuegos con temáticas explícitamente sexual (Stroker, 1983 \& Custer's Revenge, 1982) hasta los videojuegos que se desvinculan de los roles que tienen que reproducir y desarrollan nuevas formas de presentarse (Animal Crossing, $2001 \&$ Spore, 2008). Uno de los casos emblemáticos que aparecen en las narrativas de los gamers entrevistados, es Birdo.

Enrique: Nintendo presentó el primer personaje transgender de la historia de los videojuegos, Birdo, en el Super Mario Bros 2.

Este simpático personaje de la saga de Super Mario, hace su primera aparición en Super Mario Bros 2 del año 1988. Desde el librete de instrucción del mismo juego, podemos observar cómo los programadores definen este personaje: Birdo piensa que es una chica y escupe huevos desde su boca. Prefiere ser llamado "Birdetta". La misma Nintendo introduce esta ambigüedad de género al presentar este personaje. El color rosa y el lazo encima de la cabeza aumenta más esta ambigüedad, si pensamos que en el año 1988, Super Mario Bros 2 fue uno de los juegos más vendido de la época, con 10 millones de copias y parece sorprendente como la marca ha querido arriesgarse introduciendo un personaje transgender en una época todavía muy marcada por prejuicios y visiones estereotipas del género.

Birdo ha marcado un antes y un después en la historia de los videojuegos y en los Games Studies (Vitali, 2010; Mosca, 2014; Shaw, 2010). Se ha estudiado la evolución performativa del género de personaje en el transcurso de la historia de la saga de Mario. Por ejemplo en los sucesivos juegos Nintendo reconoce Birdo como hembra. En Mario Tennis, Birdo se convierte en la novia de Yoshy. Aunque en otros juegos Birdo vuelve a ser descrito como macho (Captain Rainbow).

En nuestro análisis, Birdo y Birdetta pueden ser vistos como un claro ejemplo de personaje performativo construido por la narratividad del videojuego. Judith Butler (1988) nos enseña como la construcción, y la deconstrucción, de género es siempre performativa, dependiendo de los discursos. Por la primera vez en la historia del videojuego, el género no importa y se construye de manera diferente en cada capítulo de la saga de Mario. Este ejemplo parece dar soporte a la tesis de Butler, y dato curioso, que tanto Birdo como el concepto de performance en el género aparecen en el mismo año, el 1988. En una de sus últimas apariciones, ya no se intenta categorizar a Birdo en una sola categoría, sino que se define como "Una criatura rosa de género indeterminado que algunos dicen que se llamaría Birdetta" (Super Smash Bros Brawl, 2008).

En el mismo videojuego en que apareció Birdo por primera vez, Super Mario Bros 2, hay otra situación digna de ser analizada por las dinámicas Genero/sociedad/videojuegos, y es el caso de Princess Toadstool. Como podemos ver en la imagen siguiente, uno de los cuatro personajes que se podían elegir en este juego, era esta princesita muy estereotipada proveniente de los cuentos de hadas.

Naturalmente cada personaje del juego tenía unas habilidades muy diferentes, relacionadas al salto y a la fuerza. Princess Toadstool tenía una fuerza y un salto inferior a los demás personajes (incentivando esta visión estereotipada de género) pero tenía la habilidad única de flotar en el aire por 1,5 segundo. Simulaba el vuelo por breves instantes. En el estudio que hizo Kinder (1991) sobre la manera de elegir un personaje 
en los videojuegos, menciona que esta diferencia funcional es la que hace elegir la mayoría de las veces a su hijo de ocho años y a sus amigos a ella en lugar que los demás, sin preocuparse por el riesgo de la identificación transgender por parte de los compañeros. Esta dinámica nos hace reflexionar sobre las características del personaje que podemos elegir, que muchas veces son más importantes que su apariencia. Si para un niño de ocho años, menciona Kinder (1991), no resulta atractivo elegir una princesa en lugar del héroe gordito de la saga, Mario. Pero esta diferencia se borra cuando gracias a las habilidades de la princesa puede avanzar en el juego con muchos menos problemas que con los demás personajes. En la imagen anterior, podemos ver como la habilidad de flotar en el aire de la princesa ayuda en el momento de atrapar un huevo que sale de la boca de Birdo, y lanzárselo de nuevo para derrotarlo y avanza de nivel. Podemos decir que Super Mario Bros 2, es un caso emblemático para empezar a estudiar la relación genero/videojuegos y punto de partida para estudiar como los personajes evolucionan en la narratividad de los videojuegos. Se pueden encontrar más ejemplos en otras sagas como la de Sonic, Metal Gear Solid o GTA. Finalmente es nuestro "Yo" lo que construye el personaje que vemos en la pantalla, y no viceversa. En la actualidad los personajes de los videojuegos se construyen y se deconstruyen como una performance de género butleriana.

El género es negociado, puesto en escena, no sólo por las chicas sino por todos en el acto de jugar. Esta definición de género amplia la visión que se ha utilizado habitualmente a la hora de analizar la relación de las chicas con los videojuegos, Butler lo presenta así:

"[El] género es lo que uno asume, invariablemente, bajo coacción, a diario e incesantemente, con ansiedad y placer, pero tomar erróneamente este acto continuo por un dato natural y lingüístico es renunciar al poder de ampliar el campo cultural con performances subversivas de diversas clases" (Butler, 1998: 314).

Hace faltar replantear y repensar diferentes categorías de análisis respecto a la relación entre videojuegos y género para no caer en la reproducción de ciertos discursos estereotipados y enfoques analíticos estáticos. En primer lugar, la esencia de los "videojuegos" tal y cómo se presentan en esta retrospectiva de la identidad "gamer" no responde a la situación actual. Hay una gran variedad de géneros que implican diferentes contenidos, temáticas y mecánicas de juego que no existían en los 90. En la actualidad la industria del videojuego se mueve en la búsqueda de nuevos mercados más allá del jugador "hardcore", ese aficionado a los videojuegos que podía dedicarle cientos de horas a su mayor entretenimiento. Esa búsqueda ha encontrado en el jugador "casual" un usuario igualmente legítimo que busca otro tipo de entretenimientos a partir de nuevas formas y temáticas en los videojuegos.

La problemática consiste en saber diferenciar correctamente que un jugador "casual" no tiene que ser obligatoriamente una chica, ni todos los jugadores "hardcore" son necesariamente chicos. No se puede confundir la implicación e inmersión en el juego con las características y gustos de cada género. Lo que sí aparece es una dificultad de las chicas para poder convertirse en jugadoras "hardcore" porque este hecho entra en conflicto con su construcción del rol de género. Para poder llegar a esos niveles de experiencia e inmersión las chicas tienen que adquirir ciertos comportamientos que son considerados masculinos, promocionados y valorados en ellos pero censurados y reprimidos en ellas.

\section{Impacto e Innovación Social del videojuego en España}

La ludología no deja de alertar acerca de que la narración no es la única forma de contar cosas, los discursos se transmiten de diversas maneras a partir de las reglas, las estructuras y las experiencias del juego. A esto hay que añadirle dos advertencias que todos los investigadores en videojuegos deberían tener en cuenta, "el juego es social y físico" (Frasca, 2009: 42). El juego siempre es con otros, en su presencia física o no, y el juego implica algún tipo de acción performativa. Todas estas líneas alertan de que siempre existe algún tipo de discurso que se produce y se transmite en los videojuegos, y que estos generan acciones diversas. Es innegable el impacto social que los videojuegos han tenido y tienen en la sociedad: "Mis amigos y yo jugamos a videojuegos como razón para estar juntos" (Sherry, 2001). Pero en aquel entonces, la época que mencionamos en esta arqueología cultural, no era tan evidente. Los videojuegos tenían un aspecto marginal en los medios de comunicación y en la investigación. Los gamers eran una minoría y muy lejos de ser considerados como miembros de un grupo "mainstream". Pero en las narrativas que hemos recogido emerge esta importancia de jugar a videojuegos, y el impacto que esta acción ha tenido en las vidas de los gamers y en la sociedad en general.

Julia: En esa época en el 98-99 no se veía mucho que las chicas fuesen gamer como se dice ahora así que no tenía mucho con quien estar compartiendo ya que los niños no lo veían bien, pero en el colegio tenía un grupo de 3 o 4 donde comentábamos las cosas sobre los próximos 
lanzamientos y especulábamos como iba a ser etc... Yo en ese tiempo por lo que se ve era la más enteradilla ya que disponía de un ordenador propio y me buscaba las castañas yo sola, me pasaba el día mirando noticias en la página web de Meristation que a día de hoy sigue abierta desde el 97 y en trucoteca básicamente es lo mismo dar noticias pero con guías y trucos.

Esta gamer nos ayuda a entender cómo jugar a videojuegos no existe en un espacio social vacío, siempre tiene un lugar y un tiempo en que esta acción se realiza. La importancia también de la construcción de redes lejanas de la sociedad patriarcal y conservadora de aquel entonces en la sociedad española. No era sólo una actividad de "chicos", sino que un grupito de chicas gamers existía y funcionaba con las mismas dinámicas que los grupos de los chicos. La información circulaba de la misma manera, incluso para el tema de buscar trucos. Sólo en el interior de la propia red se pueden compartir trucos, información y estrategias. La red social es básica para los gamers (Jessen, 1998).

Una de las primeras críticas desde esta perspectiva la realizó Selnow (1984) en un trabajo donde defendía la hipótesis respecto del hecho que jugar videojuegos es básicamente una actividad solitaria. De esta forma, a más tiempo pasaba el jugador inmerso en los videojuegos más desatendía y se alejaba de sus amigos y demás interacciones sociales. Además, esta dinámica generaba en el videojugador la pérdida de habilidades sociales necesarias para la vida normal. Como ya se ha visto en este repaso a las investigaciones en el ámbito psicológico, los mismos resultados demuestran hasta qué punto los prejuicios sobre los efectos de los videojuegos poco tienen que ver con la realidad del jugador.

Los trabajos realizados respecto de la influencia de los videojuegos en el entorno social han encontrado datos que contradicen la idea del aislamiento social. Para empezar, los videojugadores prefieren jugar con amigos u otros jugadores (Tejeiro, 1998; De Waal, 1995) más que jugar solos con la computadora o consola. Además, el videojuego se convierte en un elemento que posibilita nuevas relaciones con otros usuarios, ya sea a partir de compartir la misma afición con nuevos amigos o generar amistad con otros jugadores. El desarrollo del juego en red y a través de internet a facilitado la interconexión de personas con los mismos gustos y aficiones (Kline, 1998). Es decir, al contrario de lo que se suele pensar los jugadores prefieren realizar esa actividad en compañía de amigos u otros jugadores. Además, el hecho de poder entrar en contacto con otros usuarios de los mismos videojuegos genera nuevas relaciones sociales gracias a su afición a los videojuegos.

También se ha investigado la posible influencia en la relación de los videojugadores con algunos aspectos que podrían mostrar su aislamiento social como el número de amigos o personas que conforman su entorno (Estalló, 1995) sin encontrar resultados significativos. En otras investigaciones se ha intentado ver si existía relación entre jugar a videojuegos y situaciones como la soledad, la popularidad o el estatus social. También se ha investigado sobre rasgos de la personalidad como la timidez o la hipersensibilidad sin encontrar ninguna relación entre ambos conceptos (Van Schie \& Weigman, 1997). Tampoco se ha encontrado evidencia de que jugar a videojuegos afecte la sociabilidad o la capacidad de hacer amigos (Lin \& Lepper, 1987), ni la frecuencia con la que estos amigos se visitan o relacionan entre sí (Creasey \& Myers, 1986). Aún es más, la mayoría de las personas que se inician en la práctica de videojuegos lo hacen de la mano de algún amigo o familiar (Griffiths \& Hunt, 1995). Así, como explica Estalló (1995), los videojugadores no tienen la sensación que su afición les perjudique en sus relaciones personales.

Los videojuegos han sido un componente básico y un estímulo para la actividad social. Gracias a ellos se ha deconstruido el género y se ha luchado contra prácticas conservadoras y machistas de la sociedad. Para Saxe (1994) los videojuegos son un espacio social donde raza, género y edad no importa en el momento de compartir esta experiencia. El jugar juntos delante de una pantalla, hace olvidar el cuerpo que tienes a lado, dando importancia solamente a lo que sucede en la pantalla, las habilidades y las estrategias del gamer.

\section{Conclusiones}

Lo que acabamos de describir no es una historia de los videojuegos, sino una historia de la experiencia de jugar y compartir el juego con los demás. Un recorrido narrativo y experiencial de lo que era jugar a videojuegos, y de cómo, quizás, ha cambiado. Por esta razón, este trabajo se propone gestionar una ausencia que hay en los Games Studies, el estudio de la experiencia del video jugador y del intercambio de esta experiencia. Gracias a la arqueología cultural que hemos descrito hasta aquí, hemos podido trazar una historia de las tantas posibles sobre videojuegos, entendidos como una interacción entre discursos nostálgicos, experiencia del gamer e innovación tecnológica.

Hacer una arqueología cultural de los videojuegos es un recorrido nostálgico, es hablar de nuestros juguetes pero de una manera más social, compartiendo nuestra experiencia y de cómo aprendimos a utilizar estas máquinas. Esta manera de acercarse a los Games Studies intenta escaparse de las clasificaciones y de 
las categorías de los juegos como producto tecnológico. Muchas veces los mismos gamers trazan historias de videojuegos que no se pueden encapsular en las categorías tradicionales, sino que hay que escuchar sus discursos y trazar un recorrido epistémico a través del gamer.

En la época que hemos descrito era difícil imaginar dónde las podían llegar consolas, los videojuegos eran completamente diferentes. La narrativa era mínima, y los personajes eran construidos de manera muy básica, pero la jugabilidad era lo más importante. Es muy probable que esta sea la razón por la que se han convertido en uno de los productos culturales de mayor impacto de aquella de esa época y que ha salido mencionado en muchas entrevistas. Nintendo y su personaje más conocido, Mario, todavía siguen en el mercado contemporáneo, y teniendo éxito en las ventas. Algo que no se puede decir por otros juegos o consolas de aquel entonces. Por esta razón, nos parece oportuno considerar estos aspectos para entender la breve pero intensa historia de los videojuegos.

Y por último, queremos destacar la importancia de compartir conocimientos y estrategias sobre videojuegos como una parte importante de la interacción social de la experiencia del gamer. Sólo de esta manera, podemos entender el videojuego como una herramienta para identificar algo más importante, la sociedad y los usos sociales que se mueven en torno a un producto cultural como es el videojuego.

\section{Bibliografía}

Aarseth, E. (1997). Cybertext: perspectivas on ergodic literature. London: Johns Hopkins University Press. Belli, S., López, C. (2009). Breve Historia de los Videojuegos. Athenea Digital. 14, 159-179.

Belli, S., López, C., Feliu, J. y Gil, A. (2009). Educación y Sexualidad en las nuevas tecnologías de la información y la comunicación. Sexo y Emociones delante de una pantalla plana. Revista Transatlántica de Educación. 6, 103-113.

Bolter, J.D. \& Grusin, R. (2000). Remediation. Understanding New Media. Cambridge (Massch.) \& London: The MIT Press.

Butler, J. (1988). Performative acts and gender constitution: An essay in phenomenology and feminist theory. Theatre journal, 40(4), 519-531.

Butler, J. (1998). Actos performativos y construcción del género. Debate Feminista, (18), 296-314.

Bryce, J. \& Rutter, J. (2003). The Gendering of Computer Gaming: Experience and Space. En Scott Fleming e Ian Jones (Eds.), Leisure Cultures: Investigations in Sport, Media and Technology (pp. 3-22). Eastbourne: Leisure Studies Association.

Consalvo, M. (2007). Cheating. Boston: MIT Press.

Creasey, G. \& Mayers, B. (1986). Video Games and children: Effects on Leisure Activities, Schoolwork and Peer Involvement. Merril-Palmer Quarterly, 32(3), 251-262.

De Waal, B. (1995). Motivation for Video Game Play: A Study of Social, Cultural and Physiological Factors. Tesis de Doctorado, Simon Fraser University. Canadá. Recuperado el 12 de diciembre de 2015 en http://www.sfu.ca/ dewaal/vgame/index.htm

Estalló, J. A. (1995). Videojuegos. Efectos a largo plazo. Texto no publicado. Institut Psiquiàtric. Barcelona.

Foucault, M. (2001). Las palabras y las cosas. México: Siglo XXI.

Foucault, M. (1969 (2010)). La arqueología del saber. México: Siglo XXI.

Frasca, G. (2001a). The Sims: Grandmothers are cooler than trolls. Game Studies, 1(1). Recuperado el 12 de diciembre de 2015 en http://www.gamestudies.org/0101/frasca/

Frasca, G. (2001b). Ludology meets Narratology: similitude and difference between (video)games and narrative. Recuperado el 12 de diciembre de 2015 en http://www.ludology.org/articles/ludology.htm

Frasca, G. (2007). Play the message. Play, Game and Videogame Rhetoric. (Tesis Doctoral). IT University of Copenhagen. Copenhagen.

Frasca, G. (2009). Juego, videojuego y creaciónn de sentido. Una introducción. Comunicación, 1(7), 37-44.

Gailey, C. (1993). Mediated messages: Gender, class, and cosmos in home video games. Journal of Popular Culture, 27(1), 81-97. Recuperado el 12 de diciembre de 2015 en http://onlinelibrary.wiley.com/ doi/10.1111/j.0022-3840.1993.845217931.x/pdf

Gil, A. \& Feliu, J. (2006). Introducción: voces que hablan de espacios de encuentro. En Adriana Gil y Montse Vall-llovera (Coords.), Jóvenes en cibercafés: la dimensión física del futuro virtual (pp. 47-74). Barcelona: Editorial UOC.

Gil, A. \& Vida, T. (2007). Los videojuegos. Barcelona: Editorial UOC.

Gutiérrez, J. (2012). 8 quilates. Una historia de la edad del software español. Madrid: Polifemo. 
Griffiths, M. \& Hunt, N. (1995). Computer Game Playing in Adolescence: Prevalence and Demographic Indicators. Journal of Community and Aplied Social Psychology, (5), 189-193. Recuperado el 12 de diciembre de 2015 en http://onlinelibrary.wiley.com/doi/10.1002/casp.2450050307/pdf

Huhtamo, E. (2007). Máquinas de diversión, máquinas de problemas. Artnodes, (7), 43-60. Recuperado el 12 de diciembre de 2015 en http://www.uoc.edu/artnodes/7/dt/esp/huhtamo.pdf

Järvinen, A. (2001). "Quake goes the environment: game aesthetics and archaeologies." Digital Creativity, $12,2$.

Jessen, C. (1999). Children's Computer Culture. Three essays on children and computers. Odense: University of Southern Denmark Press.

Juul, J. (2009). A Casual Revolution: Reinventing Video Games and Their Players. Cambridge: MIT Press.

Kinder, M. (1991). Playing with power in movies, television and video games: From Muppet Babies to Tenage Mutant Ninja Turtles. Berkeley: University of California Press.

Kline, S. (1998). Video Game Culture: Leisure and Play Preferences of B.C. Teens. Simon Fraser University, Burbany, Canadá. Recuperado el 12 de diciembre de 2015 en http://www.reseau-medias.ca/ eng/issues/violence/RESOURCE/reports/vgames.htm

Lin, S. \& Lepper, M. R. (1987). Correlates of Children's Usage of Videogames and Computers. Journal of Applied Social Psychology, 17(1), 72-93. Recuperado el 12 de diciembre de 2015 en http://onlinelibrary.wiley.com/doi/10.1111/j.1559-1816.1987.tb00293.x/pdf

Livingstone, S. (2002). Young people and new media: Childhood and the changing media environment. London: Sage.

Loguidice, B. y Barton, M. (2009). Vintage Games: An insider look at the history of Grand Theft Auto, Super Mario, and the most influential games of all time. New York: Focal Press.

Mosca, I. (2014). Ontology of Gender in Computer Games. Cahiers de l'Association francaise des enseignants chercheurs en cinema et audiovisual. 6, 1-31.

Na, Misu (2001). The Home Computer in Korea: Gender, Technology, and the Family. Feminist Media Studies, 1(3), 291-306.

Navarrete, L. (2014). La imagen romántica de España en el Videojuego. Rassegna iberistica. 37(102), 215 228.

Newman, J. (2004). Videogames. New York: Routledge.

Pedja y Spidey (2015). Génesis, guía esencial de los videojuegos españoles de 8 bits. Madrid: Héroes de Papel.

Penn, Z. (2014). Atari Game Over. Los Angeles: Fuel Industries, Microsoft.

Portalo, F. (2009). Bugaboo, un hito en la Historia del Software Español. Cáceres: Universidad de Extremadura.

Pujol, G. (2010). Enriching online board games: An anthropological perspective. En Riha, D., Videogame culture and the future of interactive entertainment. Oxford: Inter-Disciplinary Press.

Revel, J. (2002). Le vocabulaire de Foucault. Paris: Ellipses.

Saxe, J. (1994). Violence in videogames: what are the pleasure?. International Conference on Violence in the Media St. John's University, 3-4 October.

Selnow, G. (1984). Playing video games. The electronic friend. Journal of Communicacion, 34(2), 148-156.

Sherry, J. L. (2001). The effects of violent video games on aggression. Human communication research, 27(3), 409-431.

Suominen, J. (2008). The Past as the Future? Nostalgia and Retrogaming in Digital Culture. Fibreculture, 11.

Suominen, J. (2012). Retrogamers. Communal Memory and Discourses of Digital History. Digital Memories, 9.

Shaw, A. (2010). Toward an Ethic of Representation: Ethics and the Representation of Marginalized Groups in Videogames. En Schrier, K. y Gibson, D., Designing Games for Ethics: Models, Techniques and Frameworks. 159-172. New York: Information Science Reference.

Tavinor, G. (2009). The Art of Videogames. London: Wiley-Blackwell.

Tejeiro, R. (1998). La práctica de videojuegos en niños del campo de Gibraltar. Algeciras: Asociación de Jugadores de Azar en Rehabilitación del Campo de Gibraltar.

Thomas, A. \& Walkerdine, V. (2000). Girls and computer games. En Proceedings of the 4th European Fe- 
minist Research Conference. Bologna, Italia. Recuperado el 12 de diciembre de 2015 en http:// www.women.it/cyberarchive/files/thomas.htm

Van Schie, E. \& Weigman, O. (1997). Children and Videogames: Leisure Activities, Aggression, Social Integration, and School Performance. Journal of Applied Social Psychology, 27(13), 1175-1194. Recuperado el 12 de diciembre de 2015 en http://doc.utwente.nl/58308/1/Schie97children.pdf Vitali, D. (2010). From Bullies to Heroes: Homophobia in Video Games. Student Pulse. 2(2), 1-8. 